\title{
Kekonvergenan Barisan Fungsi Terintegral Darboux
}

\author{
Wahidah Alwi \\ Program Studi Matematika FST, UINAM, wahidah.alwi@uin-alauddin.ac.id \\ Hikmawati Pathuddin \\ Program Studi Matematika FST, UINAM, hikmawati.pathuddin@uin-alauddin.ac.id
}

Baso Irvan

Program Studi Matematika-FST, UINAM, Basoirvan25@gmail.com

\begin{abstract}
ABSTRAK, Penelitian ini membahas tentang kekonvergenan barisan fungsi terintegral Darboux. Ada dua jenis kekonvergenan pada barisan fungsi yaitu konvergen pointwise dan konvergen seragam. Mengingat tidak semua barisan fungsi yang terintegral dan konvergen ke suatu fungsi, fungsi limitnya terintegral atau jika terintegral, nilai integralnya belum tentu sama dengan nilai limit integral barisan fungsinya. Dalam hal ini dikaji syarat cukup agar suatu fungsi terintegral Darboux pada $[a, b]$ sama dengan limit dari integral barisan fungsinya. Diperoleh bahwa untuk menjamin suatu fungsi terintegral Darboux pada $[a, b]$ sama dengan limit dari integral barisan fungsinya yaitu $\left\{f_{n}\right\}$ adalah barisan fungsi kontinu yang konvergen seragam dan $\left\{f_{n}\right\}$ terbatas pada $[a, b]$.
\end{abstract}

Kata Kunci:Kekonvergenan, Barisan Fungsi, Integral Darboux

\section{PENDAHULUAN}

Matematika ialah ilmu yang memiliki banyak sekali cabang. Salah satu cabang diantaranya adalah Analisis Real. Analisis adalah proses mengurai suatu hal menjadi berbagai unsur yang terpisah agar memenuhi sifat, hubungan dan peranannya masing- masing suatu unsur. Analisis juga sering disebut dengan pembagian. Secara persis, analisis berarti pemecah-belah atau penguraian secara jelas berbeda kebagianbagian dari suatu keseluruhan.

Salah satu cabang dari analisis yaitu barisan. Secara umum barisan adalah suatu fungsi dengan domain himpunan bilangan asli. Barisan dinotasikan dengan $\left\{x_{n}\right\}$ dan ditulis $x_{1}, x_{2}, x_{3}, \ldots, x_{n}, \ldots$ Pada umumnya telah dikenal barisan bilangan real $(X: \mathbb{N} \rightarrow \mathbb{R})$, yaitu suatu barisan dengan daerah hasil bilangan real. Barisan bilangan real $\left\{x_{n}\right\}$ dikatakan konvergen ke $x$ (dinotasikan dengan $\lim \left\{x_{n}\right\}=x$ ) jika untuk setiap bilangan positif $\varepsilon$ yang diberikan terdapat bilangan asli $N_{\varepsilon}$ sedemikian sehingga $\left|x_{n}-x\right|<\varepsilon, n \geq N_{\varepsilon}$. Dengan kata lain, jika $\lim \left\{x_{n}\right\}=x$ maka $\left\{x_{n}\right\}$ konvergen ke $x$.
Suatu barisan objeknya tidak mesti bilangan, tetapi bisa juga objek yang lain, misalnya jika objeknya fungsi maka diperoleh barisan fungsi. Di mana barisan fungsi adalah salah satu bentuk dari barisan yang objek-objeknya berupa fungsi. Bentuk fungsi yang merupakan suku ke- $n$ bergantung pada bilangan asli. Sehingga barisan fungsi dapat dituliskan dengan $\left\{f_{n}\right\}$ dan ditulis $f_{1}, f_{2}, f_{3}, \ldots, f_{n}, \ldots$.

Seperti barisan pada umumnya, kekonvergenan suatu barisan fungsi juga dapat diselidiki. Akan tetapi, tentu terdapat perbedaan perihal kekonvergenannya. Jika dianalogikan dengan suatu barisan bilangan real yang di mana terdiri dari titik-titik yang konvergen ke suatu titik, maka barisan fungsi juga akan konvergen ke suatu fungsi.

Adapun salah satu konsep yang penting pada analisis ialah teori integral. Teori integral memiliki peranan yang sangat penting dalam kehidupan. Sehingga permasalahan-permasalah yang tidak bisa diselesaikan secara langsung dapat dibawa ke dalam bentuk model matematika. Ada berbagai jenis integral yang bertumbuh pesat pada analisis salah satunya jenis integral yang banyak diketahui yaitu integral Riemann. Integral Riemann ini tidak hanya digunakan atau dipakai dalam matematika saja, akan tetapi dapat diaplikasikan dan digunakan pada bidang-bidang lainnya, seperti pada bidang teknik dan fisika.

Sebelum adanya Integral Riemann, salah satu ilmuan metematika yaitu I. Newton menyusul teori integral dari kalkulus menggunakan anti derivative. Kemudian pada tahun 1854 G. F. B. Riemann yang juga merupakan ilmuan matematika menyusun teori integral dengan cara yang berbeda yaitu menggunakan partisi-partisi. Selanjutnya pada tahun 1875, I. G. Darboux memodifikasi integral Riemann dengan terlebih 
dahulu mendefinisikan jumlah Darboux atas dan jumlah Darboux bawah serta mendefinisikan integral Darboux bawah dan integral Darboux atas.

Munculnya integral Darboux awalnya hanya untuk memperlihatkan bahwasanya semua fungsi yang monoton adalah terintegral dan memperlihatkan bahwa hasil dari fungsi yang terintegral adalah terintegral juga dengan menggunakan definisi integral Riemann itu sendiri. Sehingga digunakanlah integral Darboux yang lebih sederhana. Maka pada integral Darboux kita dapat memperlihatkan semua bagian yang berada pada Integral Riemann dan akan mudah menunjukkan bahwa suatu fungsi yang monoton itu terintegral. Kedua integral memiliki kesamaan yaitu $R \int_{a}^{b} f=D \int_{a}^{b} f$.

Adapun penelitian sebelumnya yang telah dibuktikan bahwa syarat-syarat cukup yang menjamin fungsi limit dari barisan fungsi yang terintegral Riemann pada $[a, b]$ dan nilai integralnya sama dengan nilai limit barisan fungsinya yaitu yang pertama barisan fungsi $\left\{f_{n}\right\}$ konvergen seragam pada $[a, b]$, yang kedua barisan fungsi $\left\{f_{n}\right\}$ terbatas pada $[a, b]$ dan yang terakhir barisan fungsi $\left\{f_{n}\right\}$ monoton pada $[a, b]$.

Mengingat tidak semua barisan fungsi yang terintegral dan konvergen ke suatu fungsi, fungsi limitnya terintegral atau jika terintegral, nilai integralnya belum tentu sama dengan nilai limit integral barisan fungsinya. Maka akan dikaji mengenai kekonvergenan barisan fungsi terintegral Darboux di mana pada hasilnya nanti kita akan menemukan suatu syarat cukup untuk barisan fungsi terintegral Darboux yang mengakibatkan limit fungsinya juga terintegral Darboux.

\section{TINJAUANPUSTAKA}

\section{BARISAN BILANGAN REAL}

Barisan (Sequence) pada himpunan $\mathrm{S}$ adalah suatu fungsi dengan domain $\mathrm{N}$ dan mempunyai range dalam S. Selanjutnya akan dibahas mengenai barisan di $\mathrm{R}$ dan konvergensi dari suatu barisan.

Definisi 1. Barisan bilangan real adalah suatu fungsi yang didefinisikan pada himpunan $\mathrm{N}$ dengan range dalam $R$. dengakan kata lain, barisan dalam $R$ mengawankan setiap bilangan asli $n=1,2,3, \ldots$ kepada sesuatu bilangan real. Jika $X: N \rightarrow R$ merupakan barisan, maka biasanya dituliskan dengan nilai dari $X$ pada $n$ dengan notasi $x_{n}$. Barisan sering dinotasikan dengan $X$ atau $\left\{x_{n}\right\}$ atau $\left(x_{n}: n \in N\right)$ atau \{ $\left.x_{n}\right\}$ atau $\left\{x_{n}\right\}_{n \geq 1}$. Apabila diketahui suatu barisan $Y$, artinya $Y=\left\{y_{k}\right\}$.

Definisi 2 (Limit Barisan). Diketahui $\left\{x_{n}\right\}$ barisan bilangan real. Barisan $X=\left(x_{n}\right)$ dikatakan konvergen ke $x \in R$, atau $x$ dikatakan limit barisan $\left\{x_{n}\right\}$ jika untuk setiap $\varepsilon>0$ terdapat $K(\varepsilon) \in \mathbb{N}$ sedemikian sehingga untuk setiap $n \in \mathbb{N}$ dengan $n>K(\varepsilon)$ berlaku $\mid x_{n}-$ $x \mid<\varepsilon$. Jika $x$ adalah limit sesuatu barisan $\left\{x_{n}\right\}$, maka dikatakan $\left\{x_{n}\right\}$ konvergenke $x$, atau $\left\{x_{n}\right\}$ mempunyai limit $x$. Dalam hal ini ditulis $\lim _{n \rightarrow \infty}\left\{x_{n}\right\}=x$ atau $\lim \left\{x_{n}\right\}=x$ atau $x_{n} \rightarrow$ $x$. Jika $\left\{x_{n}\right\}$ tidak konvergen, maka $\left\{x_{n}\right\}$ dikatakan divergen.

Teorema 1. Jika barisan $\left\{x_{n}\right\}$ konvergen, maka $\left\{x_{n}\right\}$ memiliki paling banyak satu limit (limitnya tunggal).

\section{Bukti :}

Andaikan $\lim _{n \rightarrow \infty}\left\{x_{n}\right\}=x^{\prime}$ dan $\lim _{n \rightarrow \infty}\left\{x_{n}\right\}=$ $x^{\prime \prime}$ dengan $x^{\prime} \neq x^{\prime \prime}$. Maka untuk sebarang $\varepsilon>0$ terdapat $K^{\prime}$ sedemikian sehingga

$$
\left|x_{n}-x^{\prime}\right|<\frac{\varepsilon}{2}
$$

untuk setiap $n \geq K^{\prime}$ dan terdapat $K^{\prime \prime}$ sedemikian sehingga

$$
\left|x_{n}-x^{\prime \prime}\right|<\frac{\varepsilon}{2}
$$

untuk setiap $n \geq K^{\prime \prime}$. Dipilih $\mathrm{K}=\max \left\{K^{\prime}, K^{\prime \prime}\right\}$. Menggunakan ketaksamaan segitiga, maka untuk $n \geq K$ diperoleh,

$$
\begin{aligned}
\left|x^{\prime}-x^{\prime \prime}\right| & =\left|x^{\prime}-x_{n}+x_{n}-x^{\prime \prime}\right| \\
& =\left|x^{\prime}-x_{n}\right|+\left|x_{n}-x^{\prime \prime}\right| \\
& =\frac{\varepsilon}{2}+\frac{\varepsilon}{2} \\
& =\varepsilon
\end{aligned}
$$

Karena berlaku untuk setiap $\varepsilon>0$, maka $x^{\prime}-$ $x^{\prime \prime}=0$ berarti $x^{\prime}=x^{\prime \prime}$. Kontradiksi dengan pengandaian. Jadi terbukti limitnya tunggal.

Definisi 3. Barisan bilangan real $X=\left\{x_{n}\right\}$ dikatakan terbatas jika terdapat bilangan real 
$M>0$ sedemikian sehingga $\left|x_{n}\right| \leq M$ untuk semua $n \in \mathbb{N}$. Oleh karena itu, barisan $\left\{x_{n}\right\}$ terbatas jika dan hanya jika himpunan $\left\{x_{n}: n \in\right.$ $\mathbb{N}\}$ merupakan subset terbatas dalam R.

Teorema 2. Jika $X=\left\{x_{n}\right\}$ konvergen maka $X=$ $\left\{x_{n}\right\}$ terbatas .

\section{Bukti :}

Diketahui $X=\left\{x_{n}\right\} \quad$ konvergen, misalkan konvergen ke $x$. Diambil $\varepsilon=1$, maka terdapat $k \in \mathbb{N}$ sedemikian sehingga untuk setiap $n \geq K$ berlaku

$$
\left|x_{n}-x\right|<1
$$

Menggunakan akibat Ketaksamaan Segitiga, maka

$$
\left|x_{n}\right|-|x|<1
$$

atau

$$
\left|x_{n}\right|<1+|x|
$$

untuk semua $n \geq K$. Pilih $M=$ $\sup \left\{x_{1}, x_{2}, \ldots, x_{k-1},|x|+1\right\}$ maka $\left|x_{n}\right| \leq M$, untuk semua $n \in \mathbb{N}$. Jadi terbukti bahwa $\left\{x_{n}\right\}$ terbatas.

Definisi 4. Barisan bilangan real $X=\left\{x_{n}\right\}$ disebut barisan Cauchy jika untuk setiap $\varepsilon>0$ terdapat $H(\varepsilon) \in \mathbb{N}$ sedemikian hingga untuk setiap $n, m \in \mathbb{N}$ dengan $n, m \geq H(\varepsilon)$ berlaku $\left|x_{n}-x_{m}\right|<\varepsilon$.

Lemma 1. Jika $X=\left\{x_{n}\right\}$ barisan bilangan real yang konvergen, maka $X$ merupakan barisan Cauchy.

\section{Bukti :}

Misalkan $x=\lim X$. Diberikan $\varepsilon>0$, maka terdapat $K\left(\frac{\varepsilon}{2}\right) \in \mathbb{N}$ sedemikian sehingga jika $n \geq K\left(\frac{\varepsilon}{2}\right)$, maka

$$
\left|x_{n}-x\right|<\frac{\varepsilon}{2}
$$

Oleh karena itu, jika $H(\varepsilon):=K\left(\frac{\varepsilon}{2}\right)$ dan jika $n, m \geq H(\varepsilon)$, maka diperoleh

$$
\begin{aligned}
\left|x_{n}-x_{m}\right|= & \left|\left(x_{n}-x\right)+\left(x_{m}-x\right)\right| \\
& =\left|x_{n}-x\right|+\left|x_{m}-x\right|<\frac{\varepsilon}{2}+\frac{\varepsilon}{2} \\
& =\varepsilon
\end{aligned}
$$

Karena berlaku untuk sebarang $\varepsilon>0$, maka terbukti bahwa $\left\{x_{n}\right\}$ barisan Cauchy.

Teorema 3. Jika $X=\left\{x_{n}\right\}$ barisan Cauchy, maka $X$ barisan terbatas.
Teorema 4 (Kriterian Konvergensi Cauchy). Barisan bilangan real $X=\left\{x_{n}\right\}$ konvergen jika dan hanya jika $X=\left\{x_{n}\right\}$ barisan Cauchy.

\section{Bukti :}

$\Rightarrow$ Jelas (Lemma 1.)

$\Leftarrow$ Diketahui $X=\left\{x_{n}\right\}$ barisan Cauchy. Diambil $\varepsilon>0$, maka terdapat $H=H(\varepsilon)>0$ sedemikian sehingga untuk setiap $n, m \in \mathbb{N}$ dengan $n, m \geq H$ berlaku

$$
\left|x_{n}-x_{m}\right|<\frac{\varepsilon}{2}
$$

Karena $X$ barisan Cauchy, maka $X$ terbatas, sehingga $X$ memuat barisan bagian $X^{\prime}=\left\{x_{n k}\right\}$ yang konvergen ke $x^{*}$. Oleh karena itu terdapat $K \geq H$ dengan $K \in\left\{n_{1}, n_{2}, n_{3}, \ldots\right\}$ sedemikian sehingga

$$
\left|x_{K}-x^{*}\right|<\frac{\varepsilon}{2}
$$

Akibatnya untuk $m=K$ diperoleh.

$$
\begin{aligned}
\left|x_{n}-x^{*}\right|= & \left.\mid x_{n}-x_{K}+x_{K}-x^{*}\right) \mid \\
& \leq\left|x_{n}-x_{K}\right|+\left|x_{K}-x^{*}\right| \\
& <\frac{\varepsilon}{2}+\frac{\varepsilon}{2}=\varepsilon
\end{aligned}
$$

Karena berlaku untuk sebarang $\varepsilon>0$, maka terbukti bahwa $X=\left\{x_{n}\right\}$ konvergen.

\section{BARISAN FUNGSI}

Barisan fungsi memiliki dua jenis kekonvergenan yaitu konvergen pointwise dan konvergen seragam.

\section{Barisan Fungsi Konvergen Pointwise}

Definisi 5. Barisan fungsi $\left\{f_{n}\right\}$ dikatakan konvergen pointwise ke suatu fungsi $f$ jika $\lim _{n \rightarrow \infty} f_{n}(x)=f(x)$, untuk setiap $x \in E$ dimana $E \subseteq \mathbb{R}$.

Lemma 2. Suatu barisan fungsi $\left\{f_{n}\right\}$ pada himpunan $E \subseteq \mathbb{R}$ konvergen ke suatu fungsi jika dan hanya jika untuk setiap $\varepsilon>0$ dan setiap $x \in E$ ada bilangan asli $N_{\varepsilon, x}$ sedemikian hingga untuk semua $n \geq N_{\varepsilon, x}$ berlaku

$$
\left|f_{n}(x)-f(x)\right|<\varepsilon . I
$$

\section{Bukti :}

$(\Rightarrow)$ Jika $\left\{f_{n}\right\} \in E \subseteq \mathbb{R}$ konvergen pointwise ke suatu fungsi maka $\forall \varepsilon>0$ dan $\forall x \in E, \exists N_{\varepsilon, x} \in$ $\mathbb{N} \ni \forall n \geq N_{\varepsilon, x}$, berlaku

$$
\left|f_{n}(x)-f(x)\right|<\varepsilon .
$$


Menurut Definisi 5. jika barisan fungsi konvergen ke suatu fungsi pada himpunan $E$ maka diperoleh

Akibatnya

$$
\lim _{n \rightarrow \infty} f_{n}(x)=f(x)
$$

$$
\left|f_{n}(x)-f(x)\right|<\varepsilon, \forall n \geq N_{\varepsilon}
$$

Untuk pertidaksamaan di atas tidak hanya nilai $\varepsilon$ yang berpengaruh untuk menentukan nilai $n$ agar pertidaksamaan tersebut dapat terpenuhi, akan tetapi didalam barisan fungsi juga terdapat nilai $x y$ ang berpengaruh terhadap pertidaksamaan, sedemikian sehingga untuk nilai $n$ bergantung terhadap nilai $x$ dan $\varepsilon$.

$(\Leftarrow)$ Jika $\forall \varepsilon>0$ dan $\forall x \in E, \exists N_{\varepsilon, x} \in \mathbb{N} \ni$ $\forall n \geq N_{\varepsilon, x}$,berlaku

$$
\left|f_{n}(x)-f(x)\right|<\varepsilon
$$

maka $\left\{f_{n}\right\}$ konvergen pointwise ke suatu fungsi. Untuk pernyataan di atas mirip dengan definisi dari suatu barisan yang konvergen di mana pada pernyataan tersebut dikatakan bahwa barisan fungsi konvergen ke suatu fungsi, pada barisan yang konvergen nilai $n$ yang memenuhi agar barisan tersebut bilangan asli $n$ selain bergantung pada $\varepsilon$, bilangan asli $n$ bergantung pada nilai $x$ yang diberikan dikarenakan untuk nilai suatu fungsi bergantung pada domain yang diberikan. Jadi, jika ada nilai $n$ yang memenuhi dengan syarat di atas maka barisan fungsi tersebut konvergen ke suatu fungsi.

\section{Barisan Fungsi Konvergen Seragam}

Definisi 6. Barisan fungsi $\left\{f_{n}\right\}$ bernilai real di $E \subseteq \mathbb{R}$. Barisan fungsi $\left\{f_{n}\right\}$ dikatakan konvergen seragam ke fungsi $f$ di $E$, jika diberikan $\varepsilon>0, \quad \exists N_{\varepsilon} \ni\left|f_{n}(x)-f(x)\right|<\varepsilon$, $\forall n \geq N_{\varepsilon}, x \in E$. Fungsi $f(x)$ merupakan nilai limit dari $f_{n}(x)$ untuk nilai $n \rightarrow \infty$.

Akibat 1. Barisan fungsi $\left\{f_{n}\right\}$ tidak konvergen seragam ke $f$ di $E$ jika dan hanya jika $\exists \varepsilon_{0}>$ $0 \ni \nexists \mathbb{N}$ yang memenuhi $\left|f_{n}(x)-f(x)\right|<$ $\varepsilon_{0} \forall n \geq N_{\varepsilon_{0}}, \forall x \in E$.

Lemma 3. Barisan fungsi $\left\{f_{n}\right\}$ tidak konvergen seragam ke fungsi $f$ di $E$ jika dan hanya jika untuk suatu $\varepsilon_{0}>0$ ada subbarisan $\left\{f_{n_{k}}\right\}$ dari $\left\{f_{n}\right\}$ dan barisan $\left\{x_{k}\right\}$ pada $E$ sedemikian sehingga berlaku $\left|f_{n_{k}}\left(x_{k}\right)-f\left(x_{k}\right)\right| \geq \varepsilon_{0}$ untuk semua $k \in \mathbb{N}$.
Bukti :

$(\Rightarrow)$ Karena barisan fungsi $\left\{f_{n}\right\}$ tidak konvergen seragam menuju fungsi $f$ maka ada $\varepsilon_{0}>0$ dan subbarisan $f_{n_{k}}$ sedemikian sehingga

$$
\left|f_{n_{k}}\left(x_{k}\right)-f\left(x_{k}\right)\right| \geq \varepsilon_{0}
$$

untuk semua $k \in \mathbb{N}$. Untuk suatu $\varepsilon_{0}$ terdapat nilai $x$ pada $E$ sedemikian sehingga pertidaksamaan tersebut bernilai lebih dari atau sama dengan $\varepsilon_{0}$. Nilai $x$ yang memenuhi pertidaksamaan di atas dapat berupa sebuah barisan $\left\{x_{k}\right\}$ pada $E$ sedemikian sehingga

$$
\left|f_{n_{k}}\left(x_{k}\right)-f\left(x_{k}\right)\right| \geq \varepsilon_{0}
$$

$(\Leftarrow)$ Andai $f_{n}$ konvergen seragam ke $f$ pada $E$, diberikan $\varepsilon_{0}>0$ maka ada $n \geq N_{\varepsilon}$ sedemikian sehingga

$$
\left|f_{n_{k}}\left(x_{k}\right)-f\left(x_{k}\right)\right|<\varepsilon_{0}, \forall x_{k} \in E
$$

Barisan fungsi $\left\{f_{n_{k}}\right\}$ merupakan sub barisan dari $\left\{f_{n}\right\}$ maka sub barisan tersebut juga konvergen

$$
\left|f_{n_{k}}\left(x_{k}\right)-f\left(x_{k}\right)\right|<\varepsilon_{0}
$$

Terjadi kontradiksi, maka pengandaian haruslah dinegasikan. Jadi terbukti bahwa $f_{n}$ tidak konvergen seragam ke $f$.

Teorema 4 (Kriteria Cauchy). Barsian fungsi $\left\{f_{n}\right\}$ konvergen seragam ke $f$ di E jika dan hanya jika diberikan $\varepsilon>0$ maka ada bilangan asli $N_{\varepsilon} \in \mathbb{N}$ sedemikan hingga $\mid f_{m}(x)-$ $f_{n}(x) \mid<\varepsilon$ untuk semua $m, n \geq N_{\varepsilon} ; x \in E$.

\section{Bukti :}

Untuk barisan fungsi $\left\{f_{n}\right\}$ konvergen seragam ke $f$ di $E$. Diberikan $\varepsilon>0 \Longrightarrow \frac{\varepsilon}{2}>0$, barisan fungsi $\left\{f_{n}\right\}$ konvergen seragam ke $f$ sedemikian sehingga

$$
\left|f_{n}(x)-f(x)\right|=\left|f(x)-f_{n}(x)\right|<\frac{\varepsilon}{2}
$$

$m$ merupakan bilangan asli juga dimana $m \geq$ $N_{\varepsilon}$, berlaku

maka diperoleh

$$
\left|f_{m}(x)-f(x)\right|<\frac{\varepsilon}{2}
$$

$$
\begin{aligned}
& \begin{aligned}
\left|f_{m}(x)-f_{n}(x)\right| & \\
& =\mid\left(f_{m}(x)-f(x)\right)+(f(x) \\
& \left.-f_{n}(x)\right) \mid
\end{aligned} \\
& \leq\left|f_{m}(x)-f(x)\right|+\left|f(x)-f_{n}(x)\right| \\
& <\frac{\varepsilon}{2}+\frac{\varepsilon}{2}=\varepsilon .
\end{aligned}
$$

Teorema 5. Barisan fungsi $\left\{f_{n}\right\}$ merupakan barisan fungsi yang kontinu dalam himpunan 
$E \subseteq \mathbb{R}$ dan konvergen seragam ke $f$ di $E$. Maka $f$ kontinu di E.

\section{Bukti :}

Barisan fungsi $\left\{f_{n}\right\}$ adalah barisan fungsi kontinu maka $f_{n}$ merupakan fungsi kontinu. Fungsi $f_{n}$ kontinu di $a \in E$, maka diberikan

$$
\varepsilon>0 \Rightarrow \frac{\varepsilon}{3}>0
$$

ada $\delta>0$ sedemikian sehingga

$$
\left|f_{n}(x)-f_{n}(a)\right|<\frac{\varepsilon}{3}
$$

untuk $|x-a|<\delta$. Barisan fungsi $\left\{f_{n}\right\}$ adalah barisan fungsi yang konvergen seragam ke $f$, jika diberikan $\varepsilon>0 \Rightarrow \frac{\varepsilon}{3}>0$, maka ada bilangan asli $N_{\varepsilon} \in \mathbb{N}$ sedemikian sehingga

$$
\left|f_{n}(x)-f(x)\right|<\frac{\varepsilon}{3}, a \in E
$$

dan $\left\{f_{n}\right\}$ konvergen seragam di $E$ maka

$$
\left|f_{n}(a)-f(a)\right|<\frac{\varepsilon}{3}
$$

Akan dibuktikan $f$ kontinu di $E$.

$$
\begin{aligned}
\mid f(x)- & f(a)|\leq| f(x)-f_{n}(x) \mid \\
& +\left|f_{n}(x)-f(a)\right| \\
& +\left|f_{n}(a)-f(a)\right| \\
& <\frac{\varepsilon}{3}+\frac{\varepsilon}{3}+\frac{\varepsilon}{3}<\varepsilon
\end{aligned}
$$

Teorema 7. Jika $\left\{f_{n}\right\}$ adalah barisan fungsi kontinu yang konvergen seragam ke suatu fungsi $f$ pada $[a, b]$ maka

$$
\lim _{n \rightarrow \infty} \int_{a}^{b} f_{n}(x) d x=\int_{a}^{b}\left[\lim _{n \rightarrow \infty} f_{n}(x)\right] d x .
$$

\section{Bukti :}

Barisan $\left\{f_{n}\right\}$ konvergen seragam maka $\left\{f_{n}\right\}$ konvergen pointwise ke $f$, sedemikian sehingga

$$
\lim _{n \rightarrow \infty} f_{n}(x)=f(x)
$$

Barisan fungsi $\left\{f_{n}\right\}$ merupakan konvergen seragam pada interval $[a, b]$. Jika diberikan

$$
\frac{\varepsilon}{b-a}>0
$$

maka ada $N_{\varepsilon} \in \mathbb{N}$ sedemikian sehingga untuk semua $x \in[a, b]$ dan $n \geq N_{\varepsilon}$ berlaku

$$
\begin{gathered}
\left|f_{n}(x)-f(x)\right|<\frac{\varepsilon}{b-a} \\
\left|\int_{a}^{b} f_{n}(x) d x-\int_{a}^{b} f(x) d x\right|<\varepsilon
\end{gathered}
$$

Jadi,

$$
\lim _{n \rightarrow \infty} \int_{a}^{b} f_{n}(x) d x=\int_{a}^{b} f(x) d x
$$

Ekuivalen dengan,

$$
\lim _{n \rightarrow \infty} \int_{a}^{b} f_{n}(x) d x=\int_{a}^{b} \lim _{n \rightarrow \infty} f_{n}(x) d x
$$

\section{INTEGRAL DARBOUX}

Definisi 7. Misal diberikan interval tertutup dan terbatas $[a, b]$. Partisi dari $[a, b]$ adalah himpunan berhingga $P$ dari titik-titik $x_{0}, x_{1}, x_{2}, \ldots, x_{n}$ di mana $a=x_{0} \leq x_{1} \leq x_{2} \leq$ $\cdots \leq x_{n-1} \leq x_{n}=b$.

Partisi $P$ terdiri dari $n+1$ titik. Jelasnya sebarang anggota partisi dari $[a, b]$ dapat berbeda jumlahnya sesuai dengan yang diinginkan.

Berdasarkan partisi di atas diperoleh subinterval-subinterval dari $[a, b]$ yaitu $\left[x_{0}, x_{1}\right],\left[x_{1}, x_{2}\right], \ldots,\left[x_{i-1}, x_{i}\right], \ldots,\left[x_{n-1}, x_{n}\right]$. subinterval ke-i $\left[x_{i-1}, x_{i}\right]$ disimbolkan dengan $\Delta x_{i}$. Simbol $\Delta x_{i}$ juga merupakan Panjang $x_{i}-$ $x_{i-1}$ sehingga $\Delta x_{i}=x_{i}-x_{i-1},(i=1,2, \ldots, n$ Misalkan $f$ adalah fungsi bernilai real yang terbatas pada $[a, b]$. Karena itu $f$ juga terbatas pada setiap subinterval yang bersesuaian dengan salah satu partisi $P$. Misal $M_{i}, m_{i}$ berturut-turut adalah supremum dan infimum dari $f$ pada $\Delta x_{i}$. Dibentuk dua jumlahan :

$$
\begin{aligned}
U(P, f) & =\sum_{i=1}^{n} M_{i} \Delta x_{i} \\
& =M_{1} \Delta x_{1},+M_{2} \Delta x_{2}+\cdots \\
& +M_{n} \Delta x_{n} \\
L(P, f) & =\sum_{i=1}^{n} m_{i} \Delta x_{i} \\
& =m_{1} \Delta x_{1},+m_{2} \Delta x_{2}+\cdots \\
& +m_{n} \Delta x_{n}
\end{aligned}
$$

Berturut-turut disebut Jumlah Darboux Atas dan Jumlah Darboux Bawah dari $f$ terhadap partisi $P$.

Jika $M, m$ adalah batas dari $f$ pada $[a, b]$, didapatkan $m \leq m_{i} \leq M_{i} \leq M$ dan mengakibatkanm $\Delta x_{i} \leq m_{i} \Delta x_{i} \leq M_{i} \Delta x_{i} \leq$ $M \Delta x_{i}$

Dengan menjumlahkan untuk $i=1,2, \ldots, n$, didapatkan $m(b-a) \leq L(P, f) \leq U(P, f) \leq$ $M(b-a)$.

Setiap partisi dapat memberikan sepasang jumlahan, jumlah Darboux atas dan jumlah Darboux bawah. Dari semua patisi pada $[a, b]$, didapatkan himpunan $U$ sebagai himpunan 
semua jumlah Darboux atas himpunan $L$ sebagai himpunan semua jumlah Darboux bawah. Ketidaksamaan di atas menunjukkan bahwa kedua himpunan ini terbatas dan setiap himpunan tersebut mempunyai supremum dan infimum. Infimum dari himpunan jumlah Darboux atas disebut Integral Darboux Atas dan supremum dari himpunan jumlah Darboux bawah disebut Integral Darboux Bawah dari $f$ pada $[a, b]$, yakni:

$\bar{D} \int_{a}^{b} f d x=\inf U=\inf \{U(P, f) ; P \quad$ adalah partisi dari $[a, b]\}$ dan

$\underline{D} \int_{a}^{b} f d x=\sup L=\sup \{L(P, f) ; P \quad$ adalah partisi dari $[a, b]\}$

Kedua integral tersebut dapat bernilai sama atau bisa saja tidak sama.

Definisi 8 (Kondisi Terintegral Darboux). Apabila integral di atas memiliki nilai yang sama, yaitu $\bar{D} \int_{a}^{b} f d x=\underline{D} \int_{a}^{b} f d x=D \int_{a}^{b} f d x$ Maka dikatakan bahwa $f$ terintegral Darboux terhadap $[a, b]$, ditulis dengan $f \in D[a, b]$.

\section{METODOLOGI}

Penelitian ini merupakan kajian teori mengenai kekonvergenan barisan fungsi yaitu kekonvergenan barisan fungsi yang terintegral Darboux. Prosedur pada penelitian ini adalah mengidentifikasi sifat dari barisan fungsi yang konvergen dan fungsi yang terintegral Darboux. Kemudian menganalisis kekonvergenan barisan fungsi yang terintegral Darboux di mana suatu fungsi yang terintegral Darboux sama dengan limit dari integral barisan fungsinya. Selanjutnya, menentukan syarat suatu fungsi terintegral Darboux sama dengan limit dari integral barisan fungsinya. Sehingga pada akhirnya diperoleh teorema kekonvergenan fungsi yang terintegral Darboux.

\section{PEMBAHASAN}

\section{SIFAT BARISAN FUNGSI KONVERGEN}

Suatu barisan fungsi memiliki dua jenis kekonvergenan yaitu konvergen pointwise dan konvergen seragam. Kekonvergenan pointwise yang dinyatakan konvergen dengan bergantung pada setiap nilai dalam interval yang diberikan. Sedangkan kekonvergenan seragam yang dinyatakan konvergen berlaku untuk semua nilai interval yang diberikan.

Berdasarkan Definisi 5, barisan fungsi $\left\{f_{n}\right\}$ dikatakan konvergen pointwise ke suatu fungsi $f$ jika $\lim _{n \rightarrow \infty} f_{n}(x)=f(x)$, untuk setiap $x \in E$ di mana $E \subseteq R$.

Kasus 1. Tentukan kekonvergenan barisan fungsi $\left\{f_{n}(x)\right\}=\left\{\frac{x^{n}}{n}\right\}$ untuk $x \in[0,1]$.

\section{Penyelesaian:}

Syarat kekonvergenan barisan fungsi yaitu $\lim _{n \rightarrow \infty} f_{n}(x)=f(x)$. Barisan fungsi $\left\{f_{n}(x)\right\}=$ $\left\{\frac{x^{n}}{n}\right\}$ konvergen ke 0 karena $\lim _{n \rightarrow \infty}\left\{\frac{x^{n}}{n}\right\}=0$ untuk $x \in[0,1]$. Sehingga $\forall \varepsilon>0, x \in E, \forall n \geq N_{\varepsilon, x}$ berlaku $\left|f_{n}(x)-f(x)\right|=\left|\frac{x^{n}}{n}-0\right| \leq \frac{1}{n}<\varepsilon$, yang berarti berdasarkan $\varepsilon$ dan $x$ yang diberikan barisan $f_{n}(x)$ konvergen pointwiseke 0 pada interval $[0,1]$ dan nilai limit untuk $n \rightarrow \infty$ dari barisan fungsi $\left\{f_{n}(x)\right\}$ atau $\lim _{n \rightarrow \infty} f_{n}(x)=0$. Untuk $x \in[1, \infty)$ barisan fungsi $\left\{f_{n}(x)\right\}=\left\{\frac{x^{n}}{n}\right\}$ tidak mempunyai nilai limit. Sebab, nilai limit $\frac{1}{\left\{f_{n}(x)\right\}}$ untuk $n \rightarrow \infty$ adalah $\lim _{n \rightarrow \infty} \frac{1}{f_{n}(x)}=$ 0 , akibatnya nilai $\lim _{n \rightarrow \infty} f_{n}(x)=\infty$. Sehingga, barisan fungsi $\left\{f_{n}(x)\right\}=\left\{\frac{x^{n}}{n}\right\} \quad$ konvergen pointwisepada interval $[0,1]$ tetapi tidak konvergen pointwisepada interval $[1, \infty)$.

Dapat dilihat bahwa ada tidaknya suatu limit pada barisan fungsi tergantung pada nilai $x$ yang diberikan. Barisan fungsi yang konvergen pointwisepada barisan fungsi sering dikatakan barisan fungsi tersebut konvergen. Selain itu pada barisan fungsi yang konvergen pointwise, nilai $n$ yang memenuhi agar barisan tersebut konvergen bergantung pada nilai $x$ dan $\varepsilon$ yang diberikan.

Selanjutnya, berdasarkan Definisi 6, barisan fungsi $\left\{f_{n}\right\}$ bernilai real di $E \subseteq \mathbb{R}$. Barisan fungsi $\left\{f_{n}\right\}$ dikatakan konvergen seragam ke fungsi $f$ di $E$, jika diberikan $\varepsilon>0, \exists N_{\varepsilon} \ni$ $\left|f_{n}(x)-f(x)\right|<\varepsilon, \quad \forall n \geq N_{\varepsilon}, \quad x \in E$. Fungsi $f(x)$ merupakan nilai limit dari $f_{n}(x)$ untuk nilai $n \rightarrow \infty$. 
Kasus 2. Tentukan kekonvergenan barisan fungsi $\left\{f_{n}(x)\right\}=\left\{\frac{x}{n}\right\}$ untuk $x \in[0,1]$.

\section{Penyelesaian:}

Syarat kekonvergenan barisan fungsi yaitu $\lim _{n \rightarrow \infty} f_{n}(x)=f(x)$. Barisan fungsi $f_{n}(x)=\left\{\frac{x}{n}\right\}$ konvergen ke 0 karena $\quad \lim _{n \rightarrow \infty} \frac{x}{n}=0, x \in$ $[0,1]$ yang berarti $\forall \varepsilon>0, x \in E, \forall n \geq N_{\varepsilon, x}$ berlaku $\left|f_{n}(x)-f(x)\right|=\left|\frac{x}{n}-0\right| \leq \frac{1}{n}<\varepsilon$, yang berarti berdasarkan $\varepsilon$ dan $x$ yang diberikan barisan $f_{n}(x)$ konvergen pointwiseke 0 pada interval $[0,1]$ karena nilai limitnya ada dan barisan fungsi $\left\{f_{n}(x)\right\}=\left\{\frac{x}{n}\right\} \quad$ konvergen seragam menuju $f(x)=0$ pada $x \in[0,1]$ karena nilai $\left|\frac{x}{n}-0\right| \leq \frac{1}{n}<\varepsilon$, yang berarti jika diambil sebarang nilai $\varepsilon>0$ ada nilai $n \geq N_{\varepsilon}$ sedemikian sehingga $\left|\frac{x}{n}-0\right|<\varepsilon$ berlaku untuk semua $x \in[0,1]$.

Dari Kasus2 menunjukkan bahwa kekonvergenan pointwise memuat kekonvergenan seragam yang berarti suatu barisan $\left\{f_{n}\right\}$ dikatakan konvergen seragam jika dan hanya jika $\left\{f_{n}\right\}$ konvergen pointwise dan ketika nilai keduanya ada maka nilainya sama.

Pada Akibat 1 dijelaskan mengenai suatu barisan fungsi yang tidak konvergen seragam, maka dapat dilihat pada Kasus 3 di bawah.

Kasus 3. Tentukan kekonvergenan barisan fungsi $f_{n}(x)=\frac{n}{1+n x}, x \in[0,1]$.

\section{Penyelesaian:}

Barisan fungsi $f_{n}(x)=\frac{n}{1+n x}, x \in[0,1] . \quad f_{n}(x)$ konvergen ke 0 dengan $\lim _{n \rightarrow \infty} \frac{n}{1+n x}=0$. Tetapi $f_{n}(x)$ tidak konvergen seragam di $x \in[0,1]$ karena jika diambil $\varepsilon=\frac{1}{8}$ dan $x=1$, maka $\left|f_{n}(x)-f(x)\right|=\left|\frac{n}{1+n}-0\right|=\frac{n}{1+n}>\frac{1}{8} . \quad$ Yang berarti tidak ada nilai $n$ yang memenuhi agar $\frac{n}{n+1}<\frac{1}{8}$.

Sehingga dapat dikatakan bahwa suatu barisan fungsi yang konvergen seragam pastilah konvergen pointwise akan tetapi barisan fungsi yang konvergen pointwise belum tentu konvergen seragam.
Setelah mengetahui barisan fungsi tersebut konvergen, selanjutnya akan dibahas mengenai sifat-sifat dari barisan konvergen. Sifat yang dimaksud adalah sifat barisan fungsi konvergen yang melekat pada fungsi kontinu dan fungsi yang terintegral. Pada Teorema 6 sudah dijelaskan bahwa barisan fungsi $\left\{f_{n}\right\}$ merupakan barisan fungsi yang kontinu dalam himpunan $E \subseteq \mathbb{R}$ dan konvergen seragam ke $f$ di $E$. Maka $f$ kontinu di $E$. Pada Teorema 7 juga dijelaskan bahwa Jika $\left\{f_{n}\right\}$ adalah barisan fungsi kontinu yang konvergen seragam ke suatu fungsi $f$ pada $[a, b]$ maka:

$$
\lim _{n \rightarrow \infty} \int_{a}^{b} f_{n}(x) d x=\int_{a}^{b}\left[\lim _{n \rightarrow \infty} f_{n}(x)\right] d x .
$$

Kasus 4. Tentukan kekonvergenan barisan fungsi $\left\{\left\{f_{n}(x)\right\}\right\}=\left\{\frac{x}{n+1}\right\}$ kontinu pada interval $[0,1]$.

\section{Penyelesaian:}

Barisan fungsi $\left\{\left\{f_{n}(x)\right\}\right\}=\left\{\frac{x}{n+1}\right\}$ kontinu pada interval $[0,1]$ karena nilai $\lim _{x \rightarrow c} f_{n}(x)=f_{n}(c)$ dan juga barisan fungsi tersebut konvergen seragam menuju ke fungsi $f$ dengan $\lim _{n \rightarrow \infty} f_{n}(x)=f(x)=0$ pada interval $[0,1]$. Nilai $\int_{0}^{1} f_{n}(x) d x=\int_{0}^{1} \frac{x}{n+1} d x=\frac{1}{2(n+1)} \quad$ dan $\lim _{n \rightarrow \infty} \int_{0}^{1} \frac{x}{n+1} d x=\lim _{n \rightarrow \infty} \frac{1}{2(n+1)}=0 . \quad$ Nilai $\int_{0}^{1} \lim _{n \rightarrow \infty} f_{n}(x) d x=\int_{0}^{1} 0 d x=0$. Hal ini menunjukkan bahwa $\quad \lim _{n \rightarrow \infty} \int_{0}^{1} f_{n}(x) d x=$ $\int_{0}^{1}\left[\lim _{n \rightarrow \infty} f_{n}(x)\right] d x$

Sehingga dapat dikatakan bahwa syarat kekonvergenan suatu barisan fungsi terintegral yaitu apabila fungsi tersebut kontinu dan konvergen seragam.

\section{SIFAT FUNGSI TERINTEGRAL DARBOUX}

Ada beberapa syarat suatu fungsi terintegral Darboux. Berdasarkan Definisi 7 menjelaskan bahwa integral Darboux untuk fungsi real yang terbatas pada suatu interval tertutup dan terbatas $[a, b]$. Selanjutnya berdasarkan Definisi 8 kondisi terintegral Darboux ketika kedua nilai integral mempunyai nilai yang sama, yang dimaksudkan dengan kedua integral tersebuat 
ialah integral Darboux bawah dan integral Darboux atas.

Kasus 5. Akan ditunjukkan bahwa fungsi konstan $k$ terintegral Darboux dengan

$$
D \int_{a}^{b} k d x=k(b-a)
$$

Untuk partisi $P$ pada interval $[a, b]$.

\section{Penyelesaian:}

$$
\begin{aligned}
& L(P, f)=k \Delta x_{1}+k \Delta x_{2}+\cdots+k \Delta x_{n} \\
& \quad=k\left(\Delta x_{1}+\Delta x_{2}+\cdots+\Delta x_{n}\right) \\
& \quad=k(b-a)
\end{aligned}
$$

Sehingga

$$
\underline{D} \int_{a}^{b} k d x=\sup L(P, f)=k(b-a)
$$

Sejalan dengan hal yang di atas, diperoleh

$$
\begin{aligned}
& \bar{D} \int_{a}^{b} k d x=\inf U(P, f) \\
= & \inf \left(k \Delta x_{1}+k \Delta x_{2}+\cdots+k \Delta x_{n}\right) \\
= & k(b-a)
\end{aligned}
$$

Jadi

$$
\underline{D} \int_{a}^{b} k d x=\bar{D} \int_{a}^{b} k=k(b-a)
$$

Yang mengakibatkan fungsi konstan $k$ terintegral dan

$$
D \int_{a}^{b} k=k(b-a)
$$

Kasus 6. Akan ditunjukkan bahwa fungsi $f$ yang didefinisikan dengan

$$
f(x)= \begin{cases}0, & \text { jika } x \text { rasional } \\ 1, & \text { jika } x \text { irasional }\end{cases}
$$

Tidak terintegral Darboux disebarang interval $[a, b]$.

\section{Penyelesaian:}

Dengan memperhatikan sebuah partisi $P$ pada interval $[a, b]$, berlaku

$$
\begin{aligned}
& U(P, f)=\sum_{i=1}^{n} M_{i} \Delta x_{i} \\
= & 1 \Delta x_{1}+1 \Delta x_{2}+\cdots+1 \Delta x_{n} \\
= & b-a
\end{aligned}
$$

$$
\bar{D} \int_{a}^{b} f d x=\inf U(P, f)=b-a
$$

Dan

$$
\begin{aligned}
& \quad \underline{D} \int_{a}^{b} f d x=\sup L(P, f) \\
= & \sup \left\{0 \Delta x_{1}+0 \Delta x_{2}+\cdots+0 \Delta x_{n}\right\} \\
= & 0
\end{aligned}
$$

Dalam hal ini digunakan sifat kepadatan bilangan real

Jadi

$$
\bar{D} \int_{a}^{b} f d x \neq \underline{D} \int_{a}^{b} f d x
$$

Sehingga dapat disimpulkan bahwa fungsi $f$ tidak terintegral Darboux.

Kasus 7. Akan ditunjukkan bahwa $x^{2}$ terintegral Darboux pada sebarang interval $[0, k]$, dimana $k>0$

\section{Penyelesaian:}

Dibuat partisi $P$ pada $[0, k]$ dengan cara membagi interval tersebut menjadi $n$ bagian yang sama, sehingga $\left[0, \frac{k}{n}, \frac{2 k}{n}, \ldots, \frac{n k}{n}\right]$ adalah partisi $P,\left[(i-1)\left(\frac{k}{n}\right)\right]^{2}$ dan $\left[i \frac{k}{n}\right]^{2}$ berturut-turut adalah batas bawah dan batas atas fungsi di $\Delta x_{i}$ dan Panjang masing-masing intervalnya adalah $\frac{k}{n}$.

$$
\begin{aligned}
U(P, & \left.x^{2}\right)=\frac{k^{3}}{n^{3}}\left(1^{2}+2^{2}+\cdots+n^{2}\right) \\
& =\frac{k^{3}}{n^{3}} \cdot \frac{n}{6}(n+1)(2 n+1) \\
& =\frac{k^{3}}{6}\left(1+\frac{1}{n}\right)\left(2+\frac{1}{n}\right)
\end{aligned}
$$

Dan

$$
\begin{aligned}
L\left(P, x^{2}\right)= & \frac{k^{3}}{n^{3}}\left\{0+1^{2}+2^{2}+\cdots+(n-1)^{2}\right\} \\
& =\frac{k^{3}}{6}\left(1-\frac{1}{n}\right)\left(2-\frac{1}{n}\right)
\end{aligned}
$$

Jadi

$$
\inf U\left(P, x^{2}\right)=\frac{k^{3}}{3}=\sup L\left(P, x^{2}\right)
$$

Sehingga dapat disimpulkan bahwa fungsi $x^{2}$ terintegral Darboux dan

$$
D \int_{a}^{b} x^{2} d x=\frac{k^{3}}{3}
$$

Sehingga 
Berdasarkan dari beberapa kasus maka dapat dikatakan bahwa syarat suatu fungsi terintegral Darboux apabila intervalnya tertutup dan terbatas $[a, b]$ serta nilai dari kedua integral Darboux atas dan integral Darboux bawahnya itu sama.

\section{KEKONVERGENAN BARISAN FUNGSI YANG TERINTEGRAL DARBOUX}

Setelah kita megetahui syarat kekonvergenan barisan suatu fungsi dan fungsi yang terintegral darboux maka kita dapat menentukan barisan fungsi apa sajakah yang dapat terintegral Darboux. Mengingat tidak semua barisan fungsi yang terintegral dan konvergen kesuatu fungsi, fungsi limitnya terintegral, atau jika terintegral, nilai integralnya belum tentu sama dengan nilai limit integral barisan fungsinya.

Pada Teorema 7 sudah di jelaskan mengenai syarat suatu barisan fungsi terintegral. Maka akan diberi beberapa kasus yang terkait tentang kekonvergenan barisan fungsi yang terintegral Darboux.

Kasus 8. Tentukan kekonvergenan barisan fungsi yang terintegral Darboux $\left\{f_{n}(x)\right\}=$ $\left\{\frac{x}{n}\right\}$ untuk $x \in[0,1]$

\section{Penyelesaian:}

Barisan Fungsi $f_{n}(x)=\frac{x}{n}$, konvergen ke 0 karena $\lim _{n \rightarrow \infty}\left\{\frac{x}{n}\right\}=0$ untuk $x \in[0,1]$. Yang berarti $\forall \varepsilon>0, x \in E, \forall n \geq N_{\varepsilon, x} \quad$ berlaku $\left|f_{n}(x)-f(x)\right|=\left|\frac{x}{n}-0\right| \leq \frac{1}{n}<\varepsilon$, yang berarti berdasarkan $\varepsilon$ dan $x$ yang diberikan barisan $f_{n}(x)$ konvergen pointwiseke 0 pada interval $[0,1]$ karena nilai limitnya ada dan barisan fungsi $\left\{f_{n}(x)\right\}=\left\{\frac{x}{n}\right\} \quad$ konvergen seragam menuju $f(x)=0$ pada $x \in[0,1]$ karena nilai $\left|\frac{x}{n}-0\right| \leq \frac{1}{n}<\varepsilon$, yang berarti jika diambil sebarang nilai $\varepsilon>0$ ada nilai $n \geq N_{\varepsilon}$ sedemikian sehingga $\left|\frac{x}{n}-0\right|<\varepsilon$ berlaku untuk semua $x \in[0,1]$.

Dibuat partisi $P$ pada interval $[0,1]$ dengan cara membagi interval tersebut menjadi $k$ bagian yang sama, sehingga $\left[0, \frac{1}{k}, \frac{2}{k}, \ldots, \frac{k}{k}=\right.$
1] adalah partisi $P$. Dapat ditulis $\quad[[(i-$ 1) $\left.\left.\left(\frac{1}{k}\right)\right],\left[(i)\left(\frac{1}{k}\right)\right]\right]$. Substitusi masuk ke fungsi sehingga, $\left[\frac{i-1}{k n}, \frac{i}{k n}\right]$ berturut-turut adalah batas bawah dan batas atas fungsi di $\Delta x_{i}$ dengan panjang masing-masing intervalnya adalah $\frac{1}{k}$.

Selanjutnya menentukan integral Darboux bawah dan integral Darboux atas. Dengan memperhatikan partisi $P$ pada interval $[0,1]$, berlaku:

$$
\begin{aligned}
U(P, f)= & \sum_{i=1}^{k} M_{i} \Delta x_{i} \\
& =\sum_{i=1}^{k} \frac{i}{k n} \cdot \frac{1}{k} \\
& =\frac{1}{k^{2} n} \sum_{i=1}^{k} \\
& =\frac{1}{k^{2} n}(1+2+\cdots+k) \\
& =\frac{1}{k^{2} n}\left[\frac{k(k+1)}{2}\right] \\
& =\frac{1}{2 n}\left[\frac{(k+1)}{k}\right] \\
& =\frac{1}{2 n}\left[1+\frac{1}{k}\right] \\
& =\frac{1}{2 n}+\frac{1}{2 k n}
\end{aligned}
$$

Maka

$$
\inf U(P, f)=\frac{1}{2 n}
$$

Selanjutnya

$$
\begin{aligned}
& L(P, f)=\sum_{i=1}^{k} m_{i} \Delta x_{i} \\
= & \sum_{i=1}^{k} \frac{i-1}{k n} \cdot \frac{1}{k} \\
= & \frac{1}{k^{2} n} \sum_{i=1}^{k} i-1 \\
= & \frac{1}{k^{2} n}(0+1+2+\cdots+(n-1)) \\
= & \frac{1}{k^{2} n}\left[\frac{k(k-1)}{2}\right] \\
= & \frac{1}{2 n}\left[\frac{(k-1)}{k}\right]
\end{aligned}
$$




$$
\begin{aligned}
& =\frac{1}{2 n}\left[1-\frac{1}{k}\right] \\
& =\frac{1}{2 n}-\frac{1}{2 k n}
\end{aligned}
$$

Maka

Diperoleh

$$
\sup L(P, f)=\frac{1}{2 n}
$$

$$
\begin{aligned}
& \bar{D} \int_{a}^{b} f_{n}(x) d x=\inf U(P, f) \\
& \bar{D} \int_{0}^{1} \frac{x}{n} d x=\frac{1}{2 n}
\end{aligned}
$$

Dan

$$
\begin{aligned}
& \underline{D} \int_{a}^{b} f_{n}(x) d x=\sup L(P, f) \\
& \underline{D} \int_{0}^{1} \frac{x}{n} d x=\frac{1}{2 n}
\end{aligned}
$$

Jadi

$$
\begin{aligned}
\bar{D} \int_{a}^{b} f_{n}(x) d x & =\underline{D} \int_{a}^{b} f_{n}(x) d x \\
& =D \int_{a}^{b} f_{n}(x) d x
\end{aligned}
$$

Sehingga terbukti bahwa $f_{n}(x)$ terintegral Darboux di interval [0,1]. Selanjutnya akan diselidiki apakah fungsi terintegral Darbouxsama dengan limit integral barisan fungsinya.

$$
\begin{gathered}
\lim _{n \rightarrow \infty} D \int_{a}^{b} f_{n}(x) d x=\lim _{n \rightarrow \infty} D \int_{0}^{1} n d x \\
=\lim _{n \rightarrow \infty}\left[\frac{1}{2 n}\right] \\
=0
\end{gathered}
$$

Dan

$$
\begin{gathered}
D \int_{a}^{b}\left[\lim _{n \rightarrow \infty} f_{n}(x)\right] d x=D \int_{0}^{1}\left[\lim _{n \rightarrow \infty} \frac{x}{n}\right] d x \\
=D \int_{0}^{1} 0 d x \\
=0
\end{gathered}
$$

Sehingga

$$
\lim _{n \rightarrow \infty} D \int_{a}^{b} f_{n}(x) d x=D \int_{a}^{b}\left[\lim _{n \rightarrow \infty} f_{n}(x)\right] d x=0
$$

Dari Kasus 8 terlihat bahwa fungsi kontinu yang konvergen seragam terbukti sebagai syarat agar suatu fungsi terintegral Darbouxpada $[a, b]$ sama dengan limit integral barisan fungsinya.
SYARAT SUATU FUNGSI TERINTEGRAL DARBOUX SAMA DENGAN LIMIT BARISAN FUNGSINYA

Berdasarkan langkah-langkah sebelumnya dan beberapa kasus yang telah dibuktikan, maka diperoleh suatu lemma sehingga syarat suatu fungsi terintegral Darboux sama dengan limit dari integral barisan fungsinya:

Lemma 5. Jika $\left\{f_{n}\right\}$ adalah barisan fungsi kontinu yang konvergen seragam ke suatu fungsi $f$ pada $[a, b]$ dan fungsinya terintegral Darboux pada $[a, b]$ maka :

$$
\lim _{n \rightarrow \infty} D \int_{a}^{b} f_{n}(x) d x=D \int_{a}^{b}\left[\lim _{n \rightarrow \infty} f_{n}(x)\right] d x
$$

\section{Bukti :}

Barisan $\left\{f_{n}\right\}$ konvergen seragam maka $\left\{f_{n}\right\}$ konvergen pointwise ke $f$, sedemikian sehingga

$$
\lim _{n \rightarrow \infty} f_{n}(x)=f(x)
$$

Barisan fungsi $\left\{f_{n}\right\}$ merupakan barisan fungsi yang konvergen seragam pada interval $[a, b]$. Jika diberikan

$$
\frac{\varepsilon}{b-a}>0
$$

maka ada $N_{\varepsilon} \in \mathbb{N}$ sedemikian sehingga untuk semua $x \in[a, b]$ dan $n \geq N_{\varepsilon}$ berlaku

$$
\begin{gathered}
\left|f_{n}(x)-f(x)\right|<\frac{\varepsilon}{b-a} \\
\left|D \int_{a}^{b} f_{n}(x) d x-D \int_{a}^{b} f(x) d x\right|<\varepsilon
\end{gathered}
$$

Jadi,

$$
\lim _{n \rightarrow \infty} D \int_{a}^{b} f_{n}(x) d x=D \int_{a}^{b} f(x) d x
$$

Ekuivalen dengan,

$$
\lim _{n \rightarrow \infty} D \int_{a}^{b} f_{n}(x) d x=D \int_{a}^{b} \lim _{n \rightarrow \infty} f_{n}(x) d x
$$

\section{KESIMPULAN}

Berdasarkan hasil dan pembahasan dapat disimpulkan bahwa syarat cukup agar suatu fungsi terintegral Darboux pada $[a, b]$ sama dengan limit barisan fungsinya yaitu: 
1. $\left\{f_{n}\right\}$ adalah barisan fungsi kontinu yang konvergen seragam

2. $\left\{f_{n}\right\}$ terbatas pada $[a, b]$

\section{DAFTAR PUSTAKA}

[1] Alwi, Wahidah. "Analisis Real". Makassar: UIN Alauddin, 2012

[2] Bartle, R., \& R.Sherbert, D. "Introduction to Real Analysis”. New York: John Wiley and Sons, 2000

[3] Endarwati, Maria Asepti. "Integral Riemann-Darboux". Yogyakarta: Universitas Sanata Dharma, 2009

[4] Goldberg, R. "Method of Real Analysis". New York: Jhon Wiley and Sons, 1976

[5] Gunawan, H. "Pengantar Analisis Real". Bandung: ITB, 2009

[6] Kosmala, W. "A Friendly Introduction to Analysis Single and Multivariable". New Jursey: Pearson Education, 2004

[7] P.Khotimah, R., Darmawijaya, S., \& Indrati, C. "Teorema-teorema Kekonvergenan Integral Riemann, Lebesque dan Henstock". Proseding Seminar Matematika Universitas Muhammadiyah Surakarta, h.184 